\title{
The Impact of Telemedicine Interventions Involving Routine Transmission of Blood Glucose Data with Clinician Feedback on Metabolic Control in Youth with Type 1 Diabetes: A Systematic Review and Meta-Analysis
}

\author{
Rayzel M. Shulman, Clodagh S. O'Gorman, and Mark R. Palmert \\ Division of Endocrinology, Department of Pediatrics, The Hospital for Sick Children, University of Toronto, 555 University Avenue, \\ Toronto, ON, Canada M5G 1 X8 \\ Correspondence should be addressed to Rayzel M. Shulman, rayzie.shulman@utoronto.ca \\ Received 18 May 2010; Accepted 13 July 2010 \\ Academic Editor: Stuart A. Weinzimer \\ Copyright ( 92010 Rayzel M. Shulman et al. This is an open access article distributed under the Creative Commons Attribution \\ License, which permits unrestricted use, distribution, and reproduction in any medium, provided the original work is properly \\ cited. \\ Our objective was to determine the impact of telemedicine (TM) interventions on the management of type 1 diabetes (T1DM) \\ in youth. We performed a systematic review of randomized trials that evaluated TM interventions involving transmission of \\ blood glucose data followed by unsolicited scheduled clinician feedback. We found no apparent effect of the TM interventions \\ on hemoglobin Alc (HbAlc), severe hypoglycemia, or diabetic ketoacidosis. The limited data available on patient satisfaction, \\ quality of life, and cost also suggested no differences between groups. It is unlikely that TM interventions, as performed in the \\ assessed studies, had a substantial effect on glycemic control or acute complications. However, it remains possible that there are \\ other benefits of TM not adequately reported, that newer TM strategies may be more effective and that interventions may benefit \\ subgroups of youth, such as those with the poor glycemic control, adolescents, or those living in remote areas.
}

\section{Introduction}

Intensive glycemic control delays and prevents microvascular and macrovascular complications of type 1 diabetes (T1DM) $[1,2]$. Despite advances in insulin preparations and delivery mechanisms for insulin, glycemic control for many pediatric patients with T1DM remains suboptimal. An international study comparing glycemic control among pediatric diabetes centres failed to show a correlation with insulin regimen, suggesting that other factors, such as the organization of delivery of care and the number of staff on the diabetes team, may be critical to attaining optimal blood glucose control [3].

The intensive treatment protocol used in the Diabetes Control and Complications Trial (DCCT) included telephone contacts to adjust insulin regimens daily for the first week and then weekly thereafter. The intervention also involved an intensive insulin regimen, increased frequency of clinic visits, and intensive blood glucose monitoring [4]. Although shown to be effective in improving glycemic control, these intensive measures are not feasible to carry out in routine practice.

Moreover, the particular challenges presented by youth with T1DM necessitate innovative management strategies [5]. One strategy for improving glycemic control is the use of telemedicine (TM). We distinguish routine T1DM management that may include solicited remote communication between patients and the diabetes team on an as-needed basis from TM interventions as defined in our study. We define TM to be the scheduled remote transmission of blood glucose (BG) data by means such as telephone, fax, mobile phone, or internet with unsolicited clinician feedback. This definition of TM is consistent with that used previously by authors of systematic reviews on this topic in the adult population with T1DM [6]. 
The impact of these types of interventions on the management of youth with T1DM is unknown. A previous systematic review that included studies published up to July 2004 in adults and youth with all types of diabetes [7] and another that included studies up to June 2003 in adults and youth with T1DM [6] both report no effect of TM on glycemic control. Since that time, new technologies such as short message service (SMS) have become more widely accessible to and utilized by youth.

Our objective is to assess the impact of TM interventions on glycemic control in youth with T1DM. We report the results of an updated systematic review that includes seven new randomized trials, focuses only on the impact of TM for T1DM in youth, and uses rigorous methodology. We also identify a need to obtain additional data on potential benefits of using telemedicine in clinical practice that extend beyond its impact on glycemic control, including engaging and empowering adolescents with novel technologies, improving patient and family quality of life, and enhancing patient and family education.

\section{Methods}

MEDLINE, EMBASE, CCTR, CINAHL (EBSCOHost), ISI Web of Science, and clinicaltrials.gov were searched up to December 21, 2009 without language restriction. Available indexing terms and text words for T1DM, TM, or related terms, and randomized controlled (RCT) or controlled clinical trials (CCT) were used. The Telemedicine Information Exchange (an international searchable database of telemedicine citations), relevant conference abstracts from 2007-2008, and reference lists of included studies were also searched.

Eligibility criteria for study inclusion were (1) youth less than 19 years with T1DM; (2) TM interventions involving scheduled routine transmission of blood glucose (BG) data with unsolicited scheduled clinician feedback; (3) inclusion of a control group that did not receive unsolicited feedback about transmitted BG data; (4) RCT or CCT. Studies were excluded if participants were pregnant or had non-T1DM. Two reviewers independently assessed studies for eligibility and validity and extracted data. Disagreements were resolved through consultation with a third reviewer. Assessment of study validity was done using the Cochrane Collaboration's tool for assessing risk of bias [8]. The Grades of Recommendation, Assessment, Development, and Evaluation (GRADE) system was used to assess the quality of the body of evidence.

The primary outcome assessed was HbAlc as a marker of long-term complications of diabetes. Treatment effect was expressed as a mean difference with $95 \%$ CI for continuous outcomes and as an odds ratio (OR) with 95\% CI for dichotomous outcomes. Meta-analyses using a randomeffects model were performed using Review Manager Version 5.0 software. We used the $I^{2}$ statistic to determine the proportion of variation in study estimates due to heterogeneity. Publication bias was assessed using funnel plots.

We hypothesized, a priori, that the following factors may explain heterogeneity (variability in participants, interventions, outcomes, study design, and risk of bias among studies): (1) age, (2) baseline HbAlc, (3) frequency of data transmission, and (4) timing of outcome measurement. Insufficient data prohibited within-study comparisons to test these hypotheses; however, between-study comparisons were performed.

\section{Results}

Of 434 studies identified, 377 were excluded after review of titles and abstracts because they were duplicates or involved the wrong population, intervention, and/or study design; 57 studies were retrieved in full text. Ten studies, involving 609 youth, met eligibility criteria [9-18] (see Figure 1 for details of the process of the selection of studies for inclusion and Table 1 for study characteristics). Data from nine of the ten studies were included in the meta-analysis. Data from one study [13] was excluded because the primary outcome, HbAlc, was reported as a modeled HbAlc effect and therefore could not statistically be combined with outcomes reported in the other studies. We report the results from this study separately.

The shortest study lasted 3 months and the longest 12 months. Most studies were 6 months in duration. All studies involved a minimum of every two-week frequency of data transmission except one that had a school-based monthly videoconference [13]. Clinic visits were held every three months, except in one study [17] in which patients attended clinic only every 6 months (Table 1). Most studies used telephone, modem, or fax to transmit data. One [18] used SMS, and one used videoconference [13]. The mean age of all participants ranged from 10 to 17 years. Most studies limited inclusion criteria to participants with suboptimal glycemic control. The mean baseline HbAlc in the studies included in the meta-analysis ranged from $8.2 \%$ to $10.2 \%$ (Table 2 ).

For all outcomes, the quality of the body of evidence was downgraded because of elements of study design and execution (Table 3 ) and because the GRADE system to assess quality of evidence necessitates a downgrade for the use of any indirect measure, such as HbAlc as a marker for long-term complications [8]. The evidence regarding severe hypoglycemia and DKA was also downgraded because rare event rates and wide confidence intervals reflect uncertainty about the estimate of effect. Therefore, for glycemic control, severe hypoglycaemia, and DKA, the quality evidence is graded as low (Table 4).

There was no statistically significant effect of TM on HbAlc (mean difference $-0.12,95 \% \mathrm{CI},-0.35$ to 0.11 ) with no contribution of statistical heterogeneity to the variability in effect estimate $\left(I^{2}=0 \%\right)$ (Figure 2(a)). Data from the single study not included in the meta-analysis [13] showed a significant difference in slope of the modelled HbAlc effect between the TM and control groups during the first six months of the intervention $(P<.02)$, but none after the six month point. The absolute decrease in the modelled HbAlc in the TM group at six months was less than $0.5 \%$.

Between-study comparisons based on age, baseline HbAlc, frequency of data transmission, and timing of 
TABLE 1: Study characteristics of the 10 studies that met inclusion criteria.

\begin{tabular}{|c|c|c|c|c|c|c|}
\hline Lead author, year (ref) & Sample size & $\begin{array}{l}\text { Frequency and mode of } \\
\text { data transmission and } \\
\text { feedback }\end{array}$ & $\begin{array}{l}\text { Duration } \\
\text { (months) }\end{array}$ & Cointerventions & $\begin{array}{l}\text { Frequency of } \\
\text { clinic visits } \\
\text { (months) }\end{array}$ & Study design \\
\hline Cadario, 2007 [9] & 28 & $\begin{array}{l}2 \text { weeks via modem, } \\
\text { clinician within } 1 \text { week }\end{array}$ & 6 & None & 3 & RCT \\
\hline Chase, 2000 [10] & 70 & $\begin{array}{l}2 \text { weeks via modem, } \\
\text { clinician by telephone }\end{array}$ & 6 & None & $\begin{array}{l}3 \text { (TM group did } \\
\text { not attend at } 3 \\
\text { months) }\end{array}$ & RCT \\
\hline Gay, 2006 [11] & 100 & $\begin{array}{l}2 \text { weeks, printout of } \\
\text { glucometer data faxed, } \\
\text { pediatric endocrinologist } \\
\text { advice by mail or phone } \\
\text { within } 5 \text { days }\end{array}$ & 6 & None & 3 & RCT \\
\hline Howe, 2005 [12] & 75 & $\begin{array}{l}\text { TM plus ED: weekly phone } \\
\text { calls for } 3 \text { months, then } \\
\text { bimonthly for } 3 \text { months } \\
\text { with diabetes nurse } \\
\text { educator }\end{array}$ & 6 & Education session & 3 & RCT, 3-arms \\
\hline Izquierdo, 2009 [13] & 41 & $\begin{array}{l}\text { Monthly videoconference } \\
\text { with immediate feedback }\end{array}$ & 12 & Education modules & 3 & $\begin{array}{c}\text { RCT, ran- } \\
\text { domization } \\
\text { at the school } \\
\text { level }\end{array}$ \\
\hline Lawson, 2005 [14] & 46 & $\begin{array}{l}\text { Weekly telephone contact } \\
\text { with diabetes nurse } \\
\text { educator }\end{array}$ & 6 & None & 3 & $\begin{array}{l}\text { RCT, single- } \\
\text { blinded, } \\
\text { parallel } \\
\text { design }\end{array}$ \\
\hline Marrero, 1995 [15] & 106 & $\begin{array}{l}2 \text { weeks, data management } \\
\text { system reviewed by } \\
\text { clinician, feedback } \\
\text { frequency determined by } \\
\text { algorithms }\end{array}$ & 12 & None & 3 & $\begin{array}{l}\text { RCT, } \\
\text { repeated } \\
\text { measures } \\
\text { design }\end{array}$ \\
\hline Nunn, 2006 [16] & 123 & $\begin{array}{l}\text { Bimonthly phone calls with } \\
\text { nurse educator }\end{array}$ & $5-8$ & $\begin{array}{l}\text { Educational program } \\
\text { by phone using } \\
\text { written material and } \\
\text { illustrations }\end{array}$ & 3 & RCT \\
\hline $\begin{array}{l}\text { Panagiotopoulos, } 2003 \\
{[17]}\end{array}$ & 50 & $\begin{array}{l}\text { Phone contact with } \\
\text { educator } 1-2 \text { times weekly }\end{array}$ & 6 & $\begin{array}{l}\text { Education provided } \\
\text { during calls and teen } \\
\text { issues addressed }\end{array}$ & 6 & RCT \\
\hline Rami, 2006 [18] & 36 & $\begin{array}{l}\text { Every BG checked or at } \\
\text { least daily via short } \\
\text { message service (SMS), } \\
\text { reviewed weekly by } \\
\text { diabetologist with SMS } \\
\text { feedback }\end{array}$ & 3 & None & 3 & $\begin{array}{l}\text { Randomized } \\
\text { cross-over } \\
\text { trial }\end{array}$ \\
\hline
\end{tabular}

HbAlc measurement revealed no differences in pooled estimates between subgroups. A post hoc between-study comparison based on whether feedback was given in realtime or if it was stored and forwarded also found no difference in HbAlc at the end of the intervention. The pooled estimate for a between-study analysis comparing studies with mean baseline $\mathrm{HbAlc}$ values $<9.0 \%$ to those with $\geq 9.0 \%$ trended toward favoring TM in the subgroup of studies with baseline HbAlc $\geq 9 \%$ (Figure 3). Publication bias was unlikely based on visual examination of the funnel plot.

Five studies reported frequency of severe hypoglycaemia and DKA $[9,10,13,14,18]$. The pooled estimates revealed no effect on severe hypoglycemia (OR 1.42, 95\% CI, 0.22 to
9.32) or DKA (OR 1.02, 95\% CI, 0.24 to 4.23 ) (Figures 2(b) and $2(\mathrm{c})$ ). A sensitivity analysis including data from the study not included in the meta-analysis [13] did not significantly change the pooled estimate for severe hypoglycemia or DKA.

However, the school-based study did find a decrease in urgent visits to the school nurses for diabetes-related problems and urgent calls to the diabetes center in the TM group compared to control [13]. Of studies included in the meta-analysis, patient satisfaction could be assessed in only one study [10] and showed no significant difference between groups. The school-based study [13] assessed patient satisfaction in the intervention group only and found that $91 \%$ of participants would use the telemedicine services again. Three 
TABLE 2: HbA1c at baseline and at end of intervention of the 9 studies included in the meta-analysis.

\begin{tabular}{|c|c|c|c|c|c|}
\hline Study & $\begin{array}{l}\text { HbAlc Inclusion } \\
\text { criteria }\end{array}$ & $\begin{array}{c}\text { Mean (SD) HbA1c } \\
\text { baseline control (\%) }\end{array}$ & $\begin{array}{l}\text { Change in mean } \\
\text { HbA1c at followup } \\
\text { control (\%) }\end{array}$ & $\begin{array}{c}\text { Mean }(\mathrm{SD}) \mathrm{HbA1c} \\
\text { baseline TM }(\%)\end{array}$ & $\begin{array}{c}\text { Change in mean } \\
\text { HbA1c at followup } \\
\text { TM }(\%)\end{array}$ \\
\hline Cadario & $>7.0 \%$ & $* 9.2$ & +0.2 & $* 9.1$ & 0 \\
\hline Chase & $7.0 \%-13.0 \%$ & $8.9(1.1)$ & -0.3 & $9.0(1.2)$ & -0.4 \\
\hline Gay & $\geq 8.0 \%$ & $9.2(0.9)$ & +0.1 & $9.3(1.3)$ & -0.2 \\
\hline Howe & $>8.5 \%$ & $\begin{array}{c}10.2(1.4), \text { ED } 10.1 \\
(1.2)\end{array}$ & -0.5 & $10.0(1.4)$ & -0.5 \\
\hline Lawson & $>8.5 \%$ & $9.7(0.6)$ & -0.1 & $10.0(1.3)$ & -0.6 \\
\hline Marrero & None defined & $9.9(1.6)$ & +0.4 & $9.4(1.9)$ & +0.6 \\
\hline Nunn & $>8.0 \%$ & $8.3(1.0)$ & +0.5 & $8.2(1.1)$ & +0.7 \\
\hline Panagiotopoulos & $\geq 8.0 \%$ but $<14.0 \%$ & $9.6(1.3)$ & -0.5 & $9.7(1.2)$ & -0.9 \\
\hline Rami & $\geq 8.0 \%$ & † $9.3(8.3-11.6)$ & +0.4 & †9.1 (8.0-11.3) & -0.1 \\
\hline
\end{tabular}

ED: education.

* No measure of variance reported.

${ }^{\dagger}$ Median (range).

TABLE 3: Risk of Assessment of Bias of the 10 studies that met inclusion criteria.

\begin{tabular}{|c|c|c|c|c|c|c|c|}
\hline Study & $\begin{array}{l}\text { Sequence } \\
\text { generation }\end{array}$ & $\begin{array}{l}\text { Allocation } \\
\text { concealment }\end{array}$ & $\begin{array}{l}\text { Blinding of } \\
\text { healthcare } \\
\text { providers }\end{array}$ & $\begin{array}{l}\text { Blinding of data } \\
\text { collectors }\end{array}$ & $\begin{array}{l}\text { Blinding of data } \\
\text { analyzers }\end{array}$ & $\begin{array}{l}\text { Incomplete } \\
\text { outcome data }\end{array}$ & $\begin{array}{l}\text { Selective } \\
\text { outcome } \\
\text { reporting }\end{array}$ \\
\hline Cadario 2007 & Unsure & Unsure & Unsure & Unsure & Unsure & Inadequate & Adequate \\
\hline Chase 2003 & Unsure & Unsure & Adequate & Unsure & Unsure & Inadequate & Adequate \\
\hline Gay 2006 & Adequate & Unsure & Unsure & Unsure & Unsure & Inadequate & Inadequate \\
\hline Howe 2005 & Adequate & Unsure & Unsure & Unsure & Unsure & Inadequate & Adequate \\
\hline Izquierdo 2009 & Unsure & Unsure & Unsure & Unsure & Unsure & Inadequate & Adequate \\
\hline Lawson 2005 & Adequate & Adequate & Adequate & Adequate & Adequate & Adequate & Adequate \\
\hline Marrero 1995 & Unsure & Unsure & Unsure & Unsure & Unsure & Unsure & Adequate \\
\hline Nunn 2006 & Adequate & Unsure & Inadequate & Unsure & Unsure & Adequate & Adequate \\
\hline $\begin{array}{l}\text { Panagiotopoulos } \\
2003\end{array}$ & Adequate & Unsure & Unsure & Unsure & Unsure & Adequate & Inadequate \\
\hline Rami 2006 & Unsure & Unsure & Unsure & Unsure & Unsure & Adequate & Adequate \\
\hline
\end{tabular}

Refer to the Cochrane Collaboration's tool for assessing risk of bias [8] for the methods used to assess the risk of bias in studies.

studies reported diabetes-related quality of life (QoL) [13$15]$, and none found significant differences between groups. Only two studies $[9,10]$ reported the cost of a clinic visit; in one of these [10], the TM group did not attend the threemonth visit with a cost savings of \$USD 142.00. Indirect costs such as missed work and school were considered [10] but not converted into dollar value nor incorporated in the overall cost calculation.

\section{Discussion}

Our results indicate that, despite a significant increase in new studies, no robust effect of TM on HbAlc was observed at the end of the intervention. It remains possible that TM has a small effect on $\mathrm{HbAlc}$, but our data argue against a large effect. Our pooled analysis includes more than 100 subjects per group giving us enough power to detect a difference in HbAlc of $0.5 \%$. Therefore, if there is an effect of the intervention on $\mathrm{HbAlc}$, it is likely less than $0.5 \%$. Our results are consistent with a recent randomized control trial examining the effect of telemedicine case management for diabetes in an older population. This study involving 1,665 subjects found an estimated $0.29 \%$ difference in $\mathrm{HbAlc}$ favoring telemedicine at the end of 5 years between groups [20].

We do not believe that lack of effect stems from selection bias among included studies. We did not expand our definition to include all uses of telemedicine, including web-based education modules and teleconferences to conduct remote clinic visits that did not necessarily include routine transmission of and feedback on blood glucose results, because that would have resulted in a collection of heterogeneous interventions among which a combination and comparison of outcomes would have been inappropriate in a meta-analysis. Moreover, upon reviewing studies that were excluded by our methods, we found that the results of those studies excluded were similar to those that were included. Three randomized controlled trials that were excluded from our review, because they did not involve transmission of blood glucose data, also found no effect on glycemic control [21-23]. 


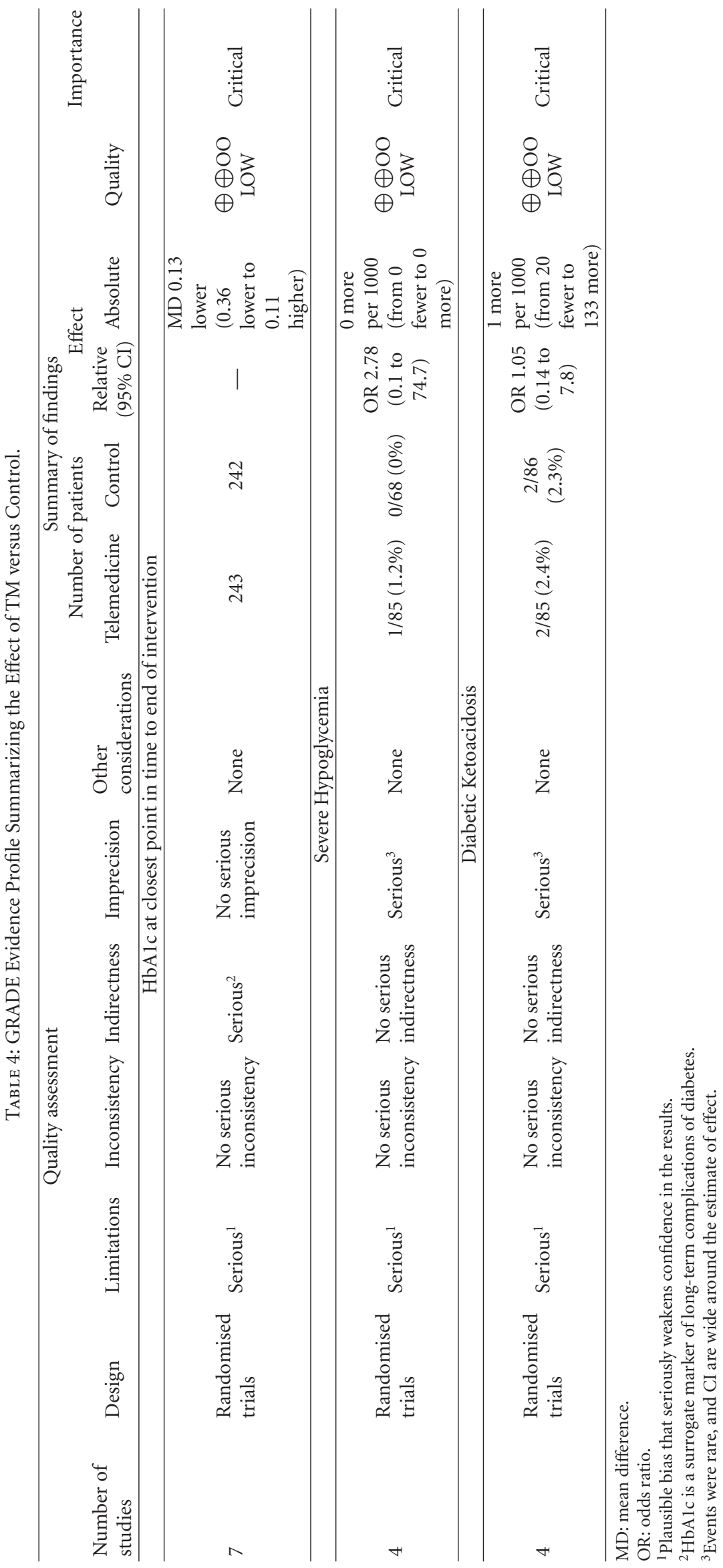




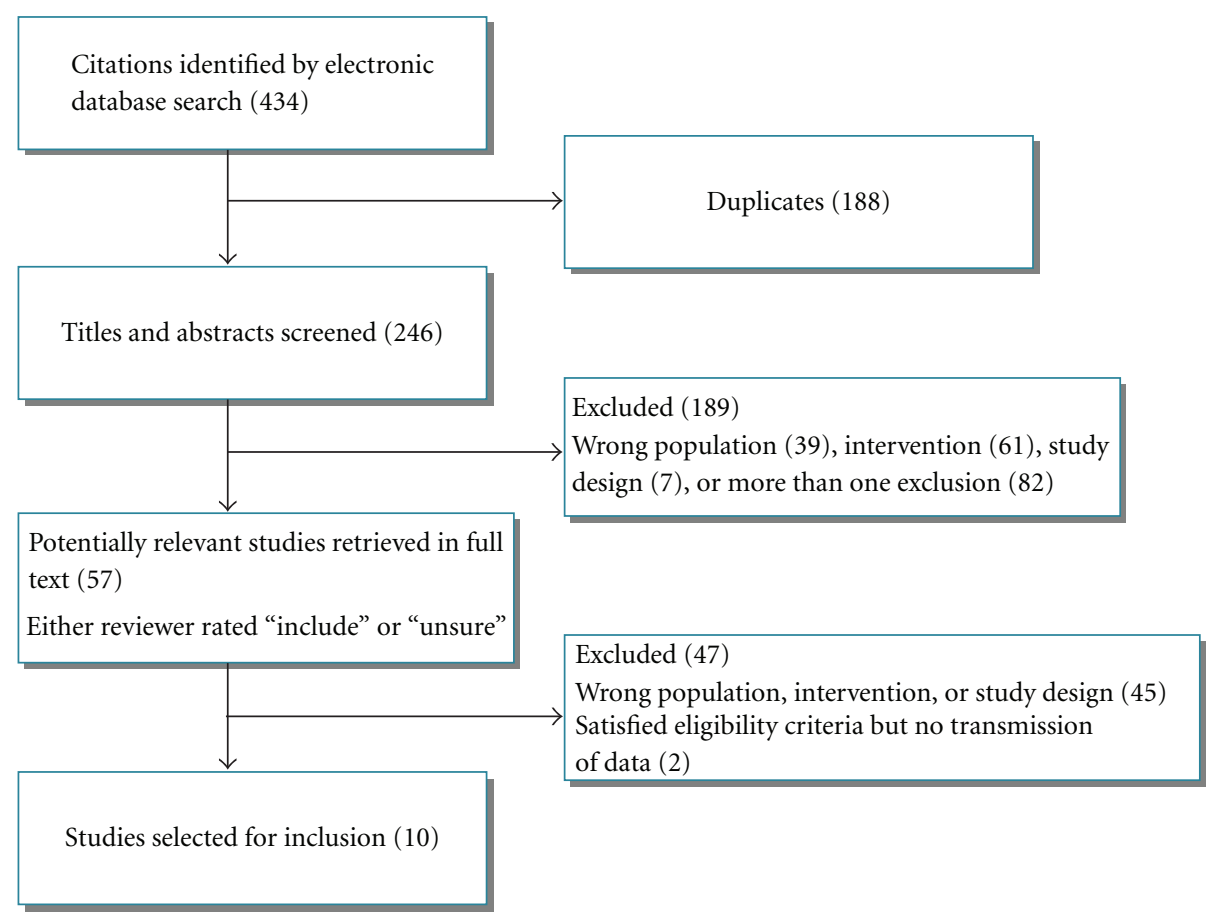

FIgURE 1: Process of selection of studies for inclusion.

Episodes of severe hypoglycemia and DKA were rare and did not differ between groups. Although data were limited, there were no apparent differences in QoL or patient satisfaction between groups. One study that used TM to replace a clinic visit suggests a reduction in cost with no increase in adverse effects. Although we might have expected adolescents to be more engaged in a telemedicine intervention compared to younger children, a between-study comparison found no differences in pooled estimates of HbAlc at the end of the intervention between subgroups based on age. However, it is possible that future, more technology-based interventions may fare better.

We used the GRADE system because it provides explicit and comprehensive criteria for assessing the quality of a body of evidence. We recognize that based on this system, the evidence in our study was determined to be low. This was, in part, due to a necessary downgrade for the use of $\mathrm{HbAlc}$ as an indirect measure. However, based on the results of the DCCT $[1,2], \mathrm{HbAlc}$ is regarded as a reliable surrogate marker for long-term complications in T1DM. Therefore, the quality of evidence is likely better than is reflected by the GRADE system.

Despite disappointing initial results, many aspects of TM interventions warrant further study. For example, betweenstudy subgroup analyses suggest a trend toward a greater effect of TM on HbAlc among participants with the highest baseline HbAlc. Thus, determining whether TM could be an important adjunct for patients with the poorest glycemic control is worth further investigation in well designed, adequately powered, long-term studies.

Although our study found no overall effect on glycemic control, it did not identify any detrimental effects. Thus, other factors to consider include whether TM may be more effective in subgroups of youth such as those living remotely from the centres where care is provided. Reducing the number of clinic visits, while maintaining glycemic control, would be clinically desirable and potentially costeffective. Thus, more studies are also needed to examine the cost-utility of TM and to determine the effects of TM interventions that replace aspects of diabetes care. Such studies should consider if TM would result in missed opportunities for screening for complications and/or education.

Finally, it will also be important to determine whether the effect of TM differs depending on the expertise of the individuals administering the TM, the frequency, and mode of data transmission (SMS, email, mobile phone, smart phone, personal digital assistant (PDA)) and whether the intervention involves the youth and/or their caregivers, or the setting. One study that examined TM in the school setting found that there was a decrease in the number of urgent visits to school nurses and calls to the diabetes centers. Successful implementation of a school-based TM intervention depends on the particular structure of the school system and may not be feasible where there are no school nurses.

It was surprising that more of the recent studies did not use more novel modes of data transmission such as SMS or other telephone-based strategies. It is possible that future studies examining the effects of newer technologies may show different results compared to the studies currently available for review. In addition to glycemic control and complications, such studies should measure other patientimportant outcomes such as QoL, diabetes knowledge, and patient satisfaction. 


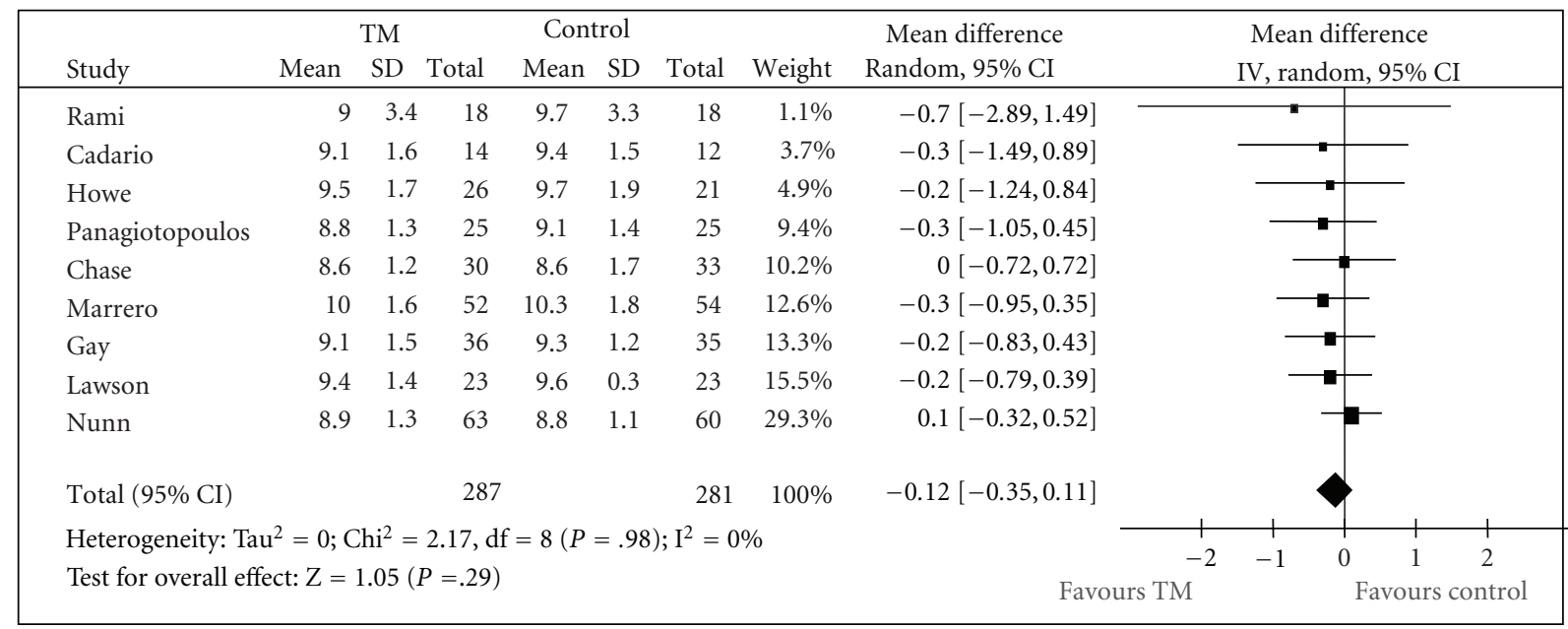

(a) HbAlc at the end of the intervention

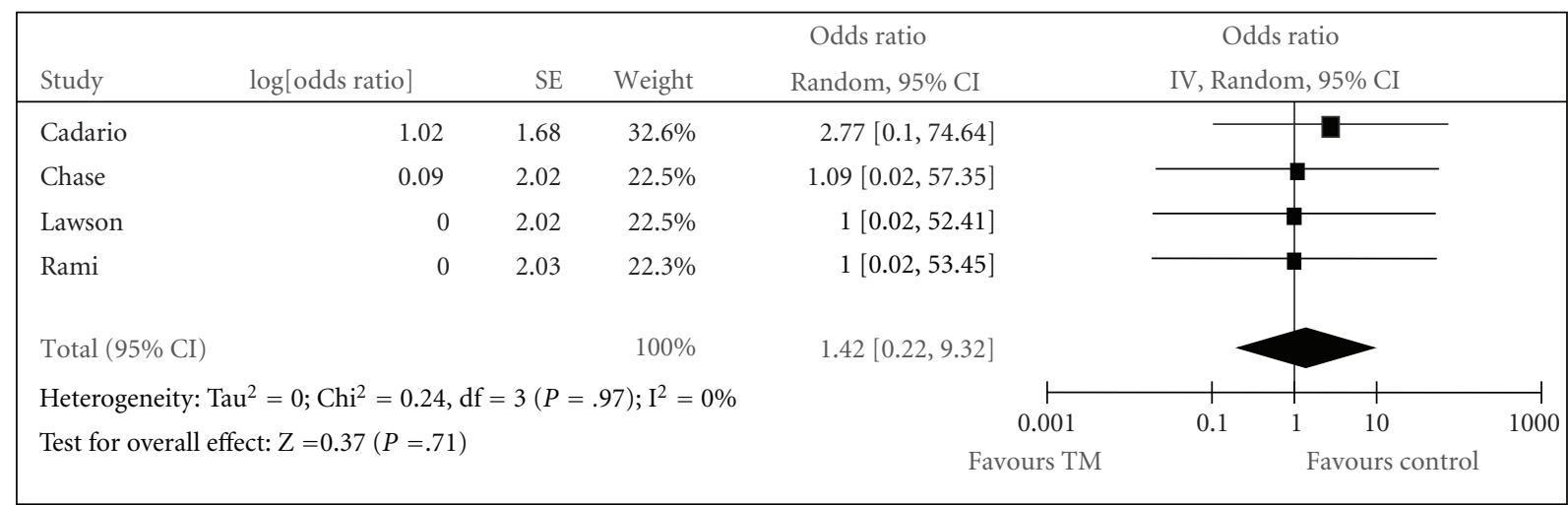

(b) Frequency of severe hypoglycemia

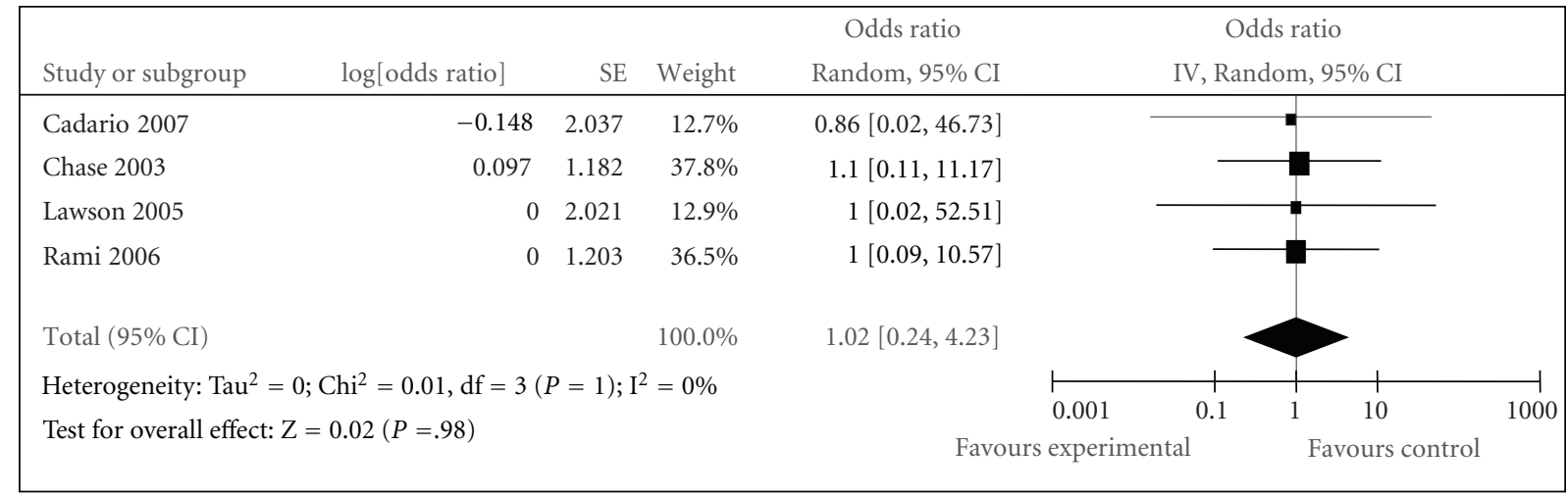

(c) Frequency of DKA

FIGURE 2: Meta-analysis of the effect of TM. Weight assigned to each study was determined using the inverse variance (IV) method which assigns weight based on the inverse of the variance of the effect estimate (one over the square of the standard error). Studies with smaller standard errors are given more weight than those with larger standard errors [19]. The size of the square representing the measure of effect is proportional to the percent weight assigned to each study on the forest plot.

\section{Conclusions}

In its recommendations about the structure of pediatric diabetes care the International Society for Pediatric and Adolescent Diabetes (ISPAD) recommends the use of TM for patients living remotely from diabetes centres and acknowledges that TM may result in improved diabetes management in all areas [5]. Our paper will likely not change current practice as diabetes care clinics will have to embrace these novel forms of communication to mirror what patients are using. Because of the small number and variable nature of the available studies, we have tried to be careful not 


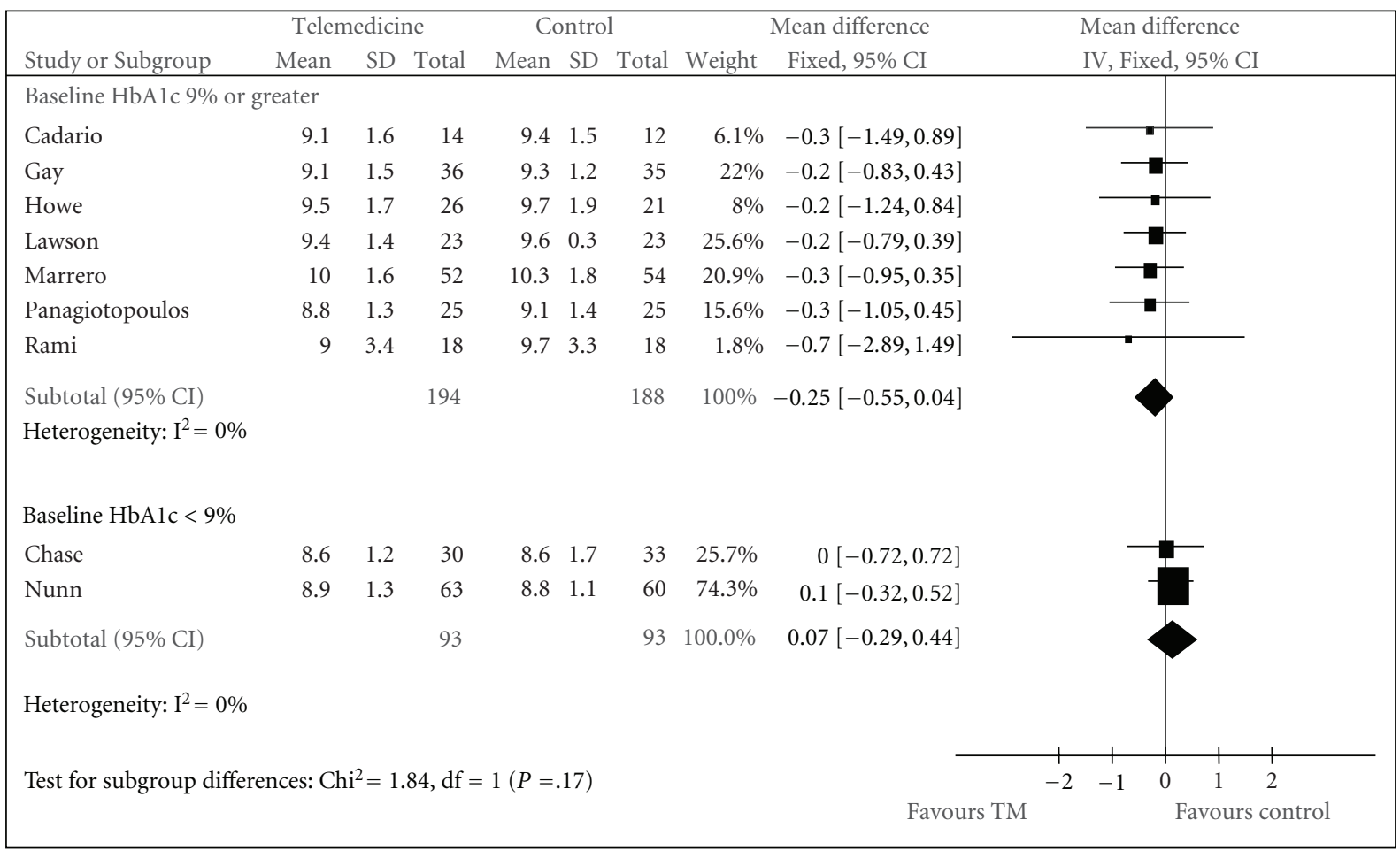

Figure 3: Meta-analysis of HbA1c at the end of the intervention with between-study comparison based on baseline HbA1c values. Weight assigned to each study was determined using the inverse variance (IV) method which assigns weight based on the inverse of the variance of the effect estimate (one over the square of the standard error). Studies with smaller standard errors are given more weight than those with larger standard errors [19]. The size of the square representing the measure of effect is proportional to the percent weight assigned to each study on the forest plot.

to overinterpret our results. However, given the potential monetary and personnel costs involved in implementing TM strategies, our paper does emphasize that TM should be well studied before it is embraced and that care must be taken to identify which subgroups of patients would maximally benefit and how we should deliver TM in the most time and resource efficient manner.

\section{Abbreviations}

(T1DM): Type 1 diabetes

(TM): Telemedicine

(HbA1c): Hemoglobin A1c

(BG): Blood glucose

(DCCT): Diabetes Control and Complications Trial

(RCT): Randomized control trial

(CCT): Controlled clinical trial

(SMS): Short message service

(QoL): Quality of life

(ISPAD): International Society for Pediatric and Adolescent Diabetes.

\section{Acknowledgments}

Elizabeth Uleryk, Library Director at The Hospital for Sick Children, was instrumental in developing the search strategy. We also thank Drs. Farid Mahmud and Denis Daneman for helpful comments and critical review of the paper.

\section{References}

[1] The Diabetes Control and Complications Trial Research Group, "The effect of intensive treatment of diabetes on the development and progression of long-term complications in insulin-dependent diabetes mellitus," The New England Journal of Medicine, vol. 329, no. 14, pp. 977-986, 1993.

[2] D. M. Nathan, P. A. Cleary, J.-Y. C. Backlund et al., "Intensive diabetes treatment and cardiovascular disease in patients with type 1 diabetes," The New England Journal of Medicine, vol. 353, no. 25, pp. 2643-2653, 2005.

[3] C. E. de Beaufort, P. G. F. Swift, C. T. Skinner et al., "Continuing stability of center differences in pediatric diabetes care: do advances in diabetes treatment improve outcome? The Hvidoere study group on childhood diabetes," Diabetes Care, vol. 30, no. 9, pp. 2245-2250, 2007.

[4] "Effect of intensive diabetes treatment on the development and progression of long-term complications in adolescents with insulin-dependent diabetes mellitus: Diabetes Control and Complications Trial. Diabetes Control and Complications Trial Research Group," Journal of Pediatrics, vol. 125, no. 2, pp. 177-188, 1994.

[5] C. Pihoker, G. Forsander, J. Wolfsdorf, and G. J. Klingensmith, "The delivery of ambulatory diabetes care to children and adolescents with diabetes," Pediatric Diabetes, vol. 10, pp. 5870, 2009.

[6] V. M. Montori, P. K. Helgemoe, G. H. Guyatt et al., “Telecare for patients with type 1 diabetes and inadequate glycemic control: a randomized controlled trial and meta-analysis," Diabetes Care, vol. 27, no. 5, pp. 1088-1094, 2004. 
[7] A. Farmer, O. J. Gibson, L. Tarassenko, and A. Neil, "A systematic review of telemedicine interventions to support blood glucose self-monitoring in diabetes," Diabetic Medicine, vol. 22, no. 10, pp. 1372-1378, 2005.

[8] J. P. T. Higgins and D. G. Altman, "Assessing risk of bias in included studies," in Cochrane Handbook for Systematic Reviews of Interventions Version 501, J. P. T. Higgins and S. Green, Eds., chapter 8, The Cochrane Collaboration, 2008.

[9] F. Cadario, M. Binotti, M. Brustia et al., "Telecare for teenagers with type 1 diabetes: a trial," Minerva Pediatrica, vol. 59, no. 4, pp. 299-305, 2007.

[10] H. P. Chase, J. A. Pearson, C. Wightman, M. D. Roberts, A. D. Oderberg, and S. K. Garg, "Modem transmission of glucose values reduces the costs and need for clinic visits," Diabetes Care, vol. 26, no. 5, pp. 1475-1479, 2003.

[11] C. L. Gay, F. Chapuis, N. Bendelac, F. Tixier, S. Treppoz, and M. Nicolino, "Reinforced follow-up for children and adolescents with type 1 diabetes and inadequate glycaemic control: a randomized controlled trial intervention via the local pharmacist and telecare," Diabetes and Metabolism, vol. 32, no. 2, pp. 159-165, 2006.

[12] C. J. Howe, A. F. Jawad, A. K. Tuttle et al., "Education and telephone case management for children with type 1 diabetes: a randomized controlled trial," Journal of Pediatric Nursing, vol. 20, no. 2, pp. 83-95, 2005.

[13] R. Izquierdo, P. C. Morin, K. Bratt et al., "School-centered telemedicine for children with type 1 diabetes mellitus," Journal of Pediatrics, vol. 155, no. 3, pp. 374-379, 2009.

[14] M. L. Lawson, N. Cohen, C. Richardson, E. Orrbine, and B. Pham, "A randomized trial of regular standardized telephone contact by a diabetes nurse educator in adolescents with poor diabetes control," Pediatric Diabetes, vol. 6, no. 1, pp. 32-40, 2005.

[15] D. G. Marrero, J. L. Vandagriff, K. Kronz et al., "Using telecommunication technology to manage children with diabetes: the Computer-Linked Outpatient Clinic (CLOC) study," The Diabetes Educator, vol. 21, no. 4, pp. 313-319, 1995.

[16] E. Nunn, B. King, C. Smart, and D. Anderson, "A randomized controlled trial of telephone calls to young patients with poorly controlled type 1 diabetes," Pediatric Diabetes, vol. 7, no. 5, pp. 254-279, 2006.

[17] C. Panagiotopoulos, J. M. Preston, L. L. Stewart, D. L. Metzger, and J.-P. Chanoine, "Weekly telephone contact by a diabetes educator in adolescents with type 1 diabetes," Canadian Journal of Diabetes, vol. 27, no. 4, pp. 422-427, 2003.

[18] B. Rami, C. Popow, W. Horn, T. Waldhoer, and E. Schober, "Telemedical support to improve glycemic control in adolescents with type 1 diabetes mellitus," European Journal of Pediatrics, vol. 165, no. 10, pp. 701-705, 2006.

[19] J. J. Deeks, J. P. T. Higgins, and D. G. Altman, "Analysing data and undertaking meta-analyses," in Cochrane Handbook for Systematic Reviews of Interventions. Version 5.0.1, J. P. T. Higgins and S. Green, Eds., The Cochrane Collaboration, 2008.

[20] S. Shea, R. S. Weinstock, J. A. Teresi et al., "A randomized trial comparing telemedicine case management with usual care in older, ethnically diverse, medically underserved patients with diabetes mellitus: 5 year results of the IDEATel study," Journal of the American Medical Informatics Association, vol. 16, no. 4, pp. 446-456, 2009.

[21] V. L. Franklin, A. Waller, C. Pagliari, and S. A. Greene, "A randomized controlled trial of Sweet Talk, a text-messaging system to support young people with diabetes," Diabetic Medicine, vol. 23, no. 12, pp. 1332-1338, 2006.
[22] L. Howells, A. C. Wilson, T. C. Skinner, R. Newton, A. D. Morris, and S. A. Greene, "A randomized control trial of the effect of negotiated telephone support on glycaemic control in young people with type 1 diabetes," Diabetic Medicine, vol. 19, no. 8, pp. 643-648, 2002.

[23] M. Graue, T. Wentzel-Larsen, B. R. Hanestad, and O. Søvik, "Evaluation of a programme of group visits and computerassisted consultations in the treatment of adolescents with type 1 diabetes," Diabetic Medicine, vol. 22, no. 11, pp. 15221529, 2005. 